\title{
Continuous low-intensity ultrasound attenuates IL- 6 and TNFa-induced catabolic effects and repairs chondral fissures in bovine osteochondral explants
}

Neety Sahu ${ }^{1}$, Hendrik J. Viljoen ${ }^{1}$ and Anuradha Subramanian ${ }^{2 *}$

\begin{abstract}
Background: Cartilage repair outcomes are compromised in a pro-inflammatory environment; therefore, the mitigation of pro-inflammatory responses is beneficial. Treatment with continuous low-intensity ultrasound (cLIUS) at the resonant frequency of $5 \mathrm{MHz}$ is proposed for the repair of chondral fissures under pro-inflammatory conditions.

Methods: Bovine osteochondral explants, concentrically incised to create chondral fissures, were maintained under CLIUS (14 kPa (5 MHz, $2.5 \mathrm{Vpp}), 20 \mathrm{~min}, 4$ times/day) for a period of 28 days in the presence or absence of cytokines, interleukin-6 (IL-6) or tumor necrosis factor (TNF)a. Outcome assessments included histological and immunohistochemical staining of the explants; and the expression of catabolic and anabolic genes by qRT-PCR in bovine chondrocytes. Cell migration was assessed by scratch assays, and by visualizing migrating cells into the hydrogel core of cartilage-hydrogel constructs.

Results: Both in the presence and absence of cytokines, higher percent apposition along with closure of fissures were noted in CLIUS-stimulated explants as compared to non-cLIUS-stimulated explants on day 14. On day 28, the percent apposition was not significantly different between unstimulated and CLIUS-stimulated explants exposed to cytokines. As compared to non-cLIUS-stimulated controls, on day 28, CLIUS preserved the distribution of proteoglycans and collagen II in explants despite exposure to cytokines. CLIUS enhanced the cell migration irrespective of cytokine treatment. IL-6 or TNFa-induced increases in MMP13 and ADAMTS4 gene expression was rescued by cLIUS stimulation in chondrocytes. Under CLIUS, TNFa-induced increase in NF-KB expression was suppressed, and the expression of collagen II and TIMP1 genes were upregulated.
\end{abstract}

Conclusion: CLIUS repaired chondral fissures, and elicited pro-anabolic and anti-catabolic effects, thus demonstrating the potential of CLIUS in improving cartilage repair outcomes.

Keywords: Inflammation, Cytokines, Ultrasound, Cartilage, Repair

\footnotetext{
*Correspondence: anu.subramanian@uah.edu

${ }^{2}$ Department of Chemical and Materials Engineering, University of Alabama

at Huntsville, Huntsville, Alabama 35899, USA

Full list of author information is available at the end of the article
}

(c) The Author(s). 2019 Open Access This article is distributed under the terms of the Creative Commons Attribution 4.0 International License (http://creativecommons.org/licenses/by/4.0/), which permits unrestricted use, distribution, and reproduction in any medium, provided you give appropriate credit to the original author(s) and the source, provide a link to the Creative Commons license, and indicate if changes were made. The Creative Commons Public Domain Dedication waiver (http://creativecommons.org/publicdomain/zero/1.0/) applies to the data made available in this article, unless otherwise stated. 


\section{Background}

Repair of damaged cartilage remains a biomedical burden as cartilage repair techniques such as microfracture, autologous chondrocyte implantation (ACI) and grafting methods including tissue-engineered approaches have failed to generate functional hyaline cartilage [1-3]. In addition to other factors that influence in-vivo repair outcomes, initial stages of repair typically take place in pro-inflammatory environment. A pro-inflammatory environment compromises the repair efforts by promoting cartilage degeneration [4-6]. Consequently, the efficacy of current and upcoming regenerative strategies is predicated on the mitigation of the detrimental effects of a pro-inflammatory joint environment to improve cartilage repair outcomes.

In an important study, the cytokine profile in patients with symptomatic cartilage defects as well as osteoarthritis (OA) revealed elevated levels of catabolic cytokines, including interleukin (IL), -6 and tumor necrosis factor (TNF) $\alpha$, in the synovial fluid and cartilage tissue extracts [7]. IL-6 and TNF $\alpha$ were also elevated in both acute and chronic phases of other joint injuries $[7,8]$. IL-6 or TNF $\alpha$-induced synthesis of matrix-degrading enzymes, such as metallopeptidases (MMPs) and A Disintegrin and Metalloproteinase with Thrombospondin Motifs (ADAMTS) aggrecanases, has been strongly implicated in cartilage degradation and OA pathogenesis [9]. Therefore, chondroprotective approaches that mitigate the catabolic effects of the pro-inflammatory joint environment are of interest.

Although the administration of non-steroidal anti-inflammatory drugs (NSAIDs) are the logical first-line treatment in an inflamed joint, low intraarticular residence time and sideeffects including gastrointestinal ulcers and cardiotoxicity necessitate alternative therapeutic efforts [10]. Recently the chondroprotective effects of pLIUS against a potent catabolic cytokine, IL-1 $\beta$ on intact cartilage explants was demonstrated in vitro [11]. However, to our knowledge, the chondroprotective effects of LIUS on other catabolic cytokines that are elevated in injured cartilage and endogenously produced by the injured cartilage itself (IL- 6 and TNF $\alpha$ ) remains uninvestigated. Further, the repair of chondral fissures under cLIUS in the presence of catabolic cytokines has not been investigated. Therefore, the current study investigated the ability of continuous LIUS (cLIUS) to promote the repair of chondral fissures in the presence of pro-inflammatory cytokines, IL-6 and TNF $\alpha$, shown to be elevated in injured cartilage and sustained for weeks post-injury [7].

Our work has shown that at any given frequency, cLIUS couples more energy than pLIUS [12] and that the bio-effects of cLIUS are frequency dependent [12-14]. Hence, differently from previous studies that employ pLIUS (1.5 MHz), our approach employed cLIUS at the cell resonant frequency of $5 \mathrm{MHz}$ where the cLIUS-induced bioeffects were reportedly maximized $[13,14]$. Further, cLIUS at $5 \mathrm{MHz}$ was shown to close chondral fissures by promoting anabolic response as evidenced by a 3.88-fold higher interfacial strength and the enhancement of the cartilage phenotype when compared to controls in an in-vitro model of integration in osteochondral explant (data under peer-review). To extend our promising findings to experimental conditions that mimic a pro-inflammatory environment, the efficacy of cLIUS at $5 \mathrm{MHz}$ in narrowing cartilage fissures while preserving the cartilage phenotype in the presence of IL-6 or TNF $\alpha$ was evaluated. Our study was predicated on the hypothesis that cLIUS enhances the cartilage phenotype, cellular migration and inhibits the expression of catabolic markers by suppressing NF- $\mathrm{KB}$ expression and upregulating the expression of anabolic markers. Thus, bovine osteochondral explants with cylindrical incisions simulating fissures in the cartilage were cultured in a cLIUS-assisted bioreactor developed at the University of Nebraska-Lincoln (UNL) [15] in the presence or absence of IL-6 or TNF $\alpha$ for a period of 28 days. Outcome analyses included histological and immunohistochemical assessments of the explants coupled with gene expression of catabolic and anabolic markers.

\section{Methods}

Creation of chondral fissures in the osteochondral explants and their culture

Bovine osteochondral explants (8 mm diameter, $1-2 \mathrm{~mm}$ cartilage thickness and $5 \mathrm{~mm}$ bone segment) from stifle joints were purchased from Articular Engineering (Northbrook, IL, USA). A full-thickness cylindrical incision in the cartilage segment of the osteochondral explant was created by a $4 \mathrm{~mm}$ biopsy punch (Integra ${ }^{\text {тм }}$ Miltex $^{\oplus}$, USA). Following incision, the osteochondral explants were categorized as (a) Control (No cytokine or no-cLIUS stimulation) (b) cLIUS (c) IL-6 (d) cLIUS +IL-6 (e) TNF $\alpha$ (f) cLIUS + TNF $\alpha$ with each study group consisting of at least 12-20 explants. The study design is schematically depicted in Fig. 1. The culture media for explants was DMEM-F12 supplemented with 10\% FBS, $1 \times$ antibiotic-antimycotic solution (Gibco, USA) and $50 \mu \mathrm{g} / \mathrm{ml}$ ascorbic acid. IL-6 or TNF $\alpha$ (R\&D Systems, Minneapolis, $\mathrm{MN}$ ) was added to appropriate wells at $20 \mathrm{ng} / \mathrm{ml}$ concentration as IL- 6 or TNF $\alpha$ dosage of $10-25 \mathrm{ng} / \mathrm{ml}$ demonstrated enhanced catabolic effects in chondrocyte cultures [16, 17]. All explants were placed in 6-well ultra-low attachment tissue culture plates (TCPs) and were either incubated in a $\mathrm{CO}_{2}$ incubator $\left(37^{\circ} \mathrm{C}, 5 \% \mathrm{CO}_{2}\right)$ or were cultured in the ultrasound-assisted bioreactor developed at UNL for 28 days. Media were replenished every 2 days. Sampling for outcome analyses was done on day 14 and day 28 of culture. 


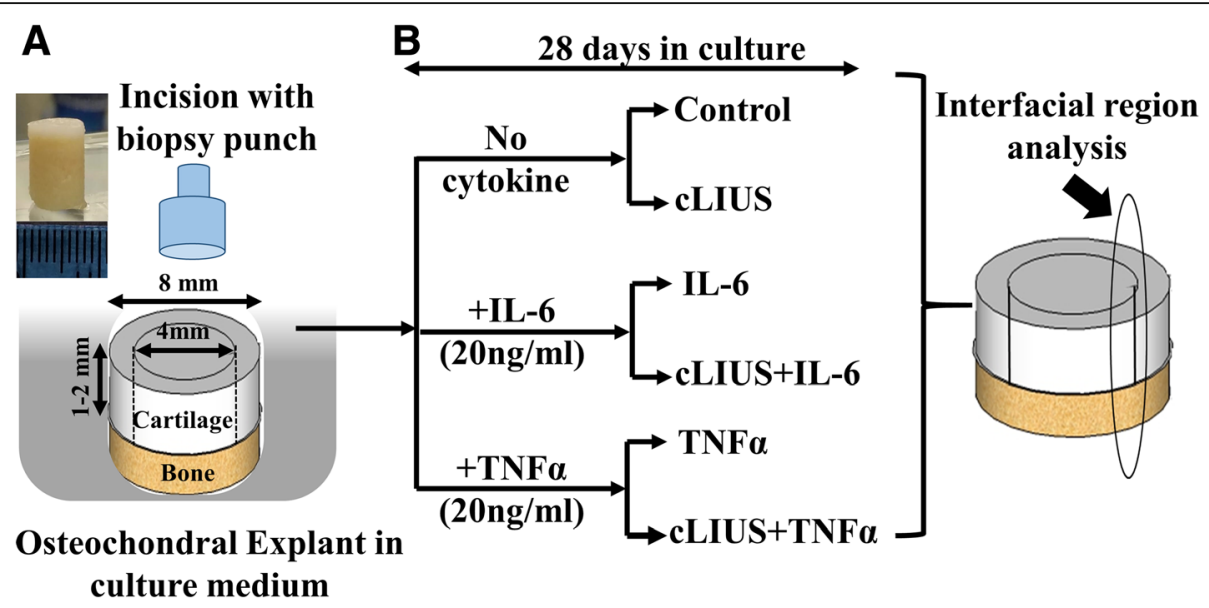

Fig. 1 Schematic representation of the repair of chondral fissures by CLIUS under catabolic conditions: (a) Figure represents a schematic model of chondral fissures in bovine osteochondral explants. A $4 \mathrm{~mm}$ full-thickness concentric incision in the cartilage portion of the osteochondral explants (8 mm diameter, 1-2 mm chondral thickness, 1-5 mm bone segment) was created using a biopsy punch. $\mathbf{b}$ Experiment design: The incised osteochondral explants were cultured in DMEM-F12 medium supplemented with 10\% FBS, $1 \times$ antibiotic-antimycotic solution and $50 \mu \mathrm{g} /$ $\mathrm{ml} \mathrm{L}$-ascorbic acid without any cytokine treatment or in the presence of either IL-6 or TNFa, each added at a concentration of $20 \mathrm{ng} / \mathrm{ml}$. cLIUS was applied at $14 \mathrm{kPa}(5 \mathrm{MHz}, 2.5 \mathrm{Vpp}), 20 \mathrm{~min}$, 4times/day for 28 days. Non-cLIUS-stimulated explants served as controls for each treatment condition

\section{Bovine articular chondrocyte culture}

Bovine articular chondrocytes were isolated from stifle joints as described elsewhere [18] and cultured in DMEM-F12 supplemented with 10\% FBS, 1× antibiotic-antimycotic solution (Gibco, USA) and $50 \mu \mathrm{g} / \mathrm{ml}$ ascorbic acid in 6 well TCPs for quantitative real time polymerase chain reaction (qRT-PCR) and scratch assays. The wells ( $n=3$ per group) were categorized as (a) Control (No cytokine or cLIUS treatment) (b) cLIUS (c) IL-6 (d) cLIUS+IL-6 (e) TNF $\alpha$ (f) cLIUS+ TNF $\alpha$ and incubated in a $\mathrm{CO}_{2}$ incubator $\left(37^{\circ} \mathrm{C}, 5 \% \mathrm{CO}_{2}\right)$. IL-6 or TNF $\alpha(20 \mathrm{ng} / \mathrm{ml})$ was added to appropriate wells.

\section{cLIUS treatment}

cLIUS $\left(<20 \mathrm{~mW} \mathrm{~cm}^{-2}\right)$ treatment was conducted in a custom-designed ultrasound-assisted bioreactor developed and characterized at the Department of Chemical and Biomolecular Engineering, UNL, USA, with operating procedures described elsewhere $[15,19]$. cLIUS was applied to explants at $5 \mathrm{MHz}$ at a constant pressure amplitude of $14 \mathrm{kPa}$ at input voltage of $2.5 \mathrm{Vpp}$ (peakto-peak voltage) for 20 min per application and 4 applications per day for a period of 28 days. In a separate experiment, explants were exposed to cLIUS at $2 \mathrm{MHz}$, a frequency outside the resonant bandwidth [13], for a period of 14 days $(n=6)$ in the cLIUS-assisted bioreactor at the constant pressure amplitude of $14 \mathrm{kPa}(6.0 \mathrm{Vpp}$, $20 \mathrm{~min}$ per application, 4 applications/day). For adherent chondrocyte cultures, cLIUS was applied using nonfocused immersion transducers (Panametrics V300, 12.7 $\mathrm{mm}$ diameters, Panametrix, Waltham, MA, USA) at 5 $\mathrm{MHz}$ and $2.5 \mathrm{Vpp}$ (or $14 \mathrm{kPa}$ ) for either 5 or $20 \mathrm{~min}$.

\section{Cell viability assay}

Cell viability was assessed by Live/Dead Viability/Cytotoxicity kit (Molecular Probes, USA) in the osteochondral explants of each group ( $n=3$ per group per time point) on day 3 and 21 of culture. The explants were incubated with $6 \mu \mathrm{M}$ calcein $^{\mathrm{AM}}$ and $4 \mu \mathrm{M}$ ethidium homodimer- 1 solution for $1 \mathrm{~h}$ at $37^{\circ} \mathrm{C}$ under aseptic conditions and visualized by confocal microscopy (Olympus $1 \times 81$ ) at $10 \times$ magnification ( $\mathrm{z}$ step size $=5 \mu \mathrm{m}, 30-40$ slices per sample, $\sim 150-200 \mu \mathrm{m}$ deep) from the top or superficial zone of cartilage at the interfacial region.

\section{Histology and immunohistochemistry}

Explants of each group ( $n=6$ per group) were typically fixed in 10\% neutral buffered formalin and decalcified using a 1:1 ratio of $8 \%$ hydrochloric acid and $8 \%$ formic acid solution. The explants were cut in half and each half was paraffin embedded, sectioned and stained at the Tissue Science Facility, University of Nebraska Medical Center (Omaha, NE, USA) using standard protocol and were reviewed by Dr. Steven H. Hinrichs (Professor, Department of pathology and microbiology, UNMC, Omaha, NE, USA). Histological staining with Alcian Blue ( $\mathrm{pH} 1)$ and Safranin O solution (Millipore, USA), and immunohistochemical staining with collagen II (ab34712, Abcam, USA) were performed on deparaffinized sections $(4 \mu \mathrm{m})$ and visualized at $2 \times$ and $20 \times$ magnification. Normal bone tissue sections served as negative control and normal colon tissue served as positive control for collagen II staining. Fast green (Millipore, USA) was used as a counterstain for Safranin O staining. All sections were stained using the same staining solution and at the same time. Representative image of 18-36 
stained interfacial regions obtained from each group $(n=6)$ was used.

\section{Quantification of the interfacial apposition}

Alcian blue stained explants were processed to quantify percent apposition by measuring the length of the bonded interfaces (no gaps) divided by the total length of the interface [20]. Apposition was defined as the region along the interface that was bonded and did not show any discernable gaps [21]. All measurements were performed using histological images at $2 \times$ magnification $(n=6)$ using ImageJ software.

\section{Quantitative real-time PCR}

Bovine articular chondrocytes were plated at an initial seeding density of $2 \times 10^{5}$ cells/well. cLIUS was applied to appropriate wells for $5 \mathrm{~min}$ followed by homogenization with Trizol. RNA was then extracted using RNeasy Mini Kit (Qiagen, USA) as per the manufacturer's protocol. Homogenates from 2 wells per group served as one replicate and 3 such replicates were used for analysis $(n=3)$. The qRT-PCR analysis was carried out on Realplex ${ }^{\mathrm{Tm}}$ real-time PCR system (Eppendorf, USA) using TaqMan ${ }^{\circ}$ RNA-to-CT ${ }^{\text {Tom }}$ 1-Step Kit (Life Technologies) as per manufacturer's guidelines. TaqMan ${ }^{\circ}$ probes and primers (Life Technologies, USA) used are as follows: GAPDH (Bt03210917_g1), MMP13 (Bt03214050_m1), ADAMTS4 (Bt03224697_m1), NF-kB (Bt03243457_m1), Collagen II (Bt03251861_m1) and TIMP1 (Bt03223720_m1). The expression of mRNA transcripts was normalized to GAPDH expression and relative expression levels were calculated using the $2^{-\Delta \Delta C t}$ method.

\section{Scratch assay}

Bovine articular chondrocytes were plated at a seeding density of $1 \times 10^{5}$ cells per well $(n=3)$. Upon $90 \%$ confluency followed by serum starvation, a scratch representing a gap was created by a $200 \mu$ l pipette tip [11]. cLIUS was applied for $20 \mathrm{~min}$ to appropriate wells. Gap area was imaged at $0 \mathrm{~h}, 6 \mathrm{~h}, 12 \mathrm{~h}, 24 \mathrm{~h}, 48 \mathrm{~h}$ and $72 \mathrm{~h}$ following the creation of scratch by bright field inverted microscope at $5 \times$ magnification and the gap area covered by migrating cells was quantified by ImageJ.

\section{Migration in cartilage-hydrogel constructs}

To visualize the migration of cells in a 3D format, a 4 $\mathrm{mm}$ central chondral region was cored out of the osteochondral explant using a biopsy punch and filled with sterile $1 \%$ agarose hydrogel. The cartilage-hydrogel constructs were categorized as (a) Control (No cytokine or cLIUS treatment) (b) cLIUS (c) IL-6 (d) cLIUS+IL-6 (e) TNF $\alpha$ (f) cLIUS+ TNF $\alpha$ and cultured in DMEM-F12 supplemented with $10 \%$ FBS, $1 \times$ antibiotic-antimycotic solution and $50 \mu \mathrm{g} / \mathrm{ml}$ ascorbic acid. IL-6 or TNFa was added at a concentration of $20 \mathrm{ng} / \mathrm{ml}$ and cLIUS was applied at $14 \mathrm{kPa}(5 \mathrm{MHz}, 2.5 \mathrm{Vpp})$ for $20 \mathrm{~min}$ to appropriate wells. The explants ( $n=3$ per group) were incubated with $6 \mu \mathrm{M}$ calcein ${ }^{\mathrm{AM}}$ and $4 \mu \mathrm{M}$ ethidium homodimer-1 solution (Live/Dead Viability/Cytotoxicity kit, Molecular Probes, USA) for $1 \mathrm{~h}$ at $37^{\circ} \mathrm{C}$ on day 24 of culture. The central region of interest was imaged by confocal microscopy (Olympus $1 \times 81$ ) at $10 \times$ magnification (5 $\mu \mathrm{m}$ Z-size, 30-40 slices). Transmitted light micrograph at $10 \times$ magnification was included to distinguish hydrogel region of the construct from the native cartilage.

\section{Statistical analysis}

The data are represented as mean $\pm 95 \%$ confidence interval where mean is calculated from 3 separate experiments, each conducted in triplicate per time point per study group. For gene expression and percent apposition, the statistical significance between the means of two groups with unequal variance was calculated by Welch's test. For NF-KB gene expression, Welch's analysis of variance (ANOVA) was used to compare control, TNF $\alpha$ and cLIUS $+\mathrm{TNF} \alpha$ groups followed by post-hoc Games-Howell test for pair-wise comparisons. For scratch assays, two-way ANOVA with post-hoc Turkey's test was used, and for cases where variance homogeneity was violated, Welch's ANOVA followed by Games-Howell test was used for pair-wise comparisons. $P$ values $<0.05$ were considered significant and exact $p$ values were indicated in the figures.

\section{Results}

To understand the reparative and chondroprotective effects offered by cLIUS, the current study investigated the repair of chondral fissures in bovine osteochondral explants in the presence of catabolic cytokines IL-6 or TNF- $\alpha$ as shown schematically in Fig. 1.

\section{Cell viability around the chondral fissures}

Cellular viability of the osteochondral explants in the vicinity of the incision was examined by live-dead assay and shown in Fig. 2. Cells surrounding the site of incision were predominantly live (green) interspersed with few dead (red) cells. On day 3 of culture, chondral fissure was noticeable as a distinct gap in all the explants (Fig. 2a-f). After 21 days in culture, explants that received cLIUS stimulation either in the presence or absence of IL- 6 or TNF $\alpha$ displayed enhanced cellular infiltration into the fissure when compared to non-cLIUS-stimulated controls (Fig. 2j-1).

\section{Repair of chondral fissures under cLIUS}

Explants were stained with alcian blue and shown in Fig. 3. Explants that received cLIUS at $5 \mathrm{MHz}$ displayed closed fissures (Fig. 3d) on day 14 and a percent apposition of $58.04 \%$ (Fig. 4) was noted. In comparison, explants that received cLIUS at the non-resonant frequency of $2 \mathrm{MHz}$ 

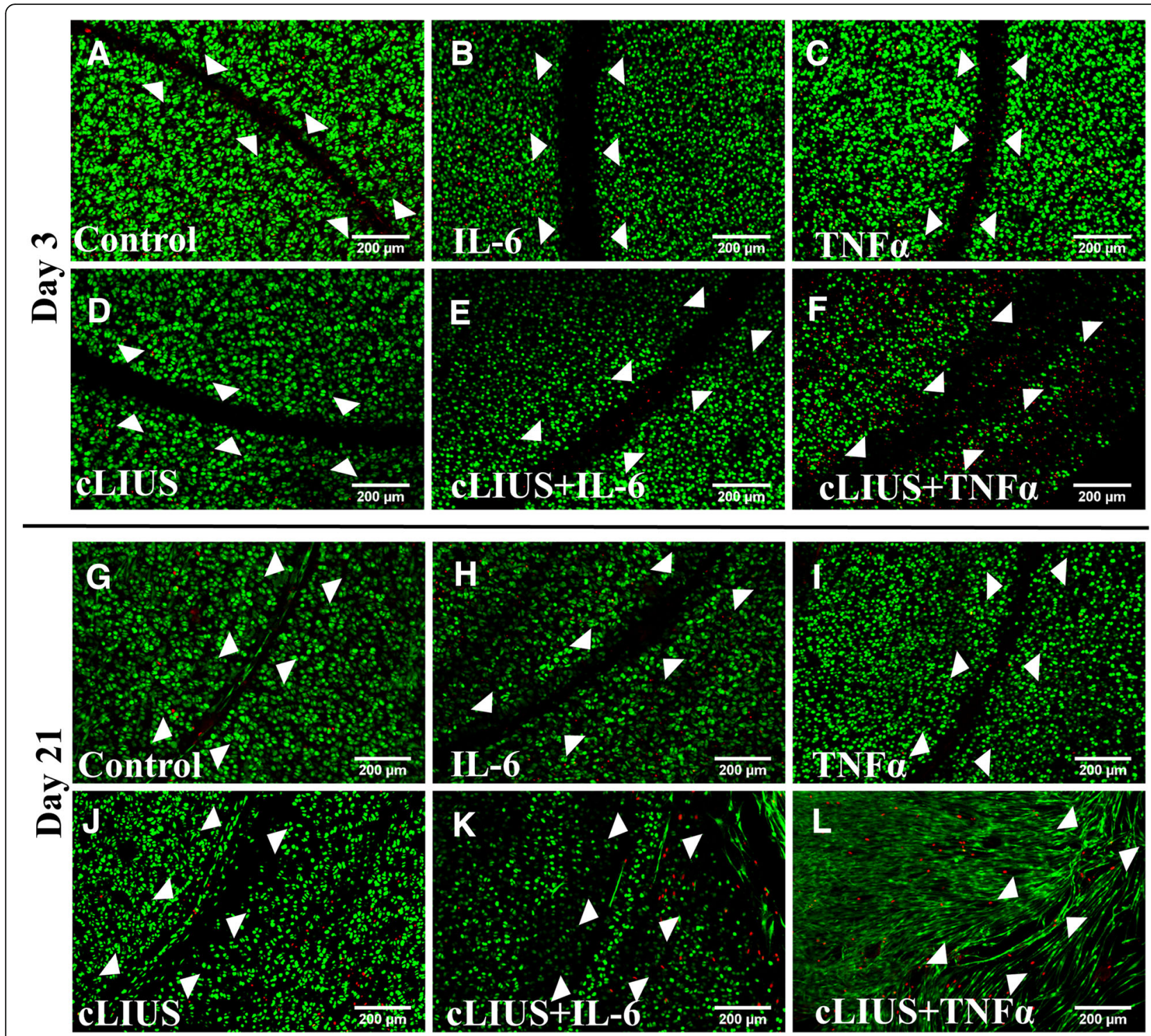

Fig. 2 Cell viability of explants. The viability of cells at the cartilage interfacial region at the vicinity of the chondral incision in osteochondral explants was viewed by live-dead staining on day 3 and day 21 of culture. Explants ( $n=3$ per group) were incubated in $6 \mu \mathrm{M}$ calcein ${ }^{\mathrm{AM}}$ and $4 \mu \mathrm{M}$ ethidium homodimer-1 solution for $1 \mathrm{~h}$ at $37^{\circ} \mathrm{C}$ under aseptic conditions. Confocal micrographs viewed from the top or superficial zone of cartilage depict live (green) cells and dead (red) cells at 10x magnification. White arrowheads indicate the leading edge of the chondral incision. Scale bar represents $200 \mu \mathrm{m}$

displayed intact gaps (Additional file 1: Figure S1) along with a percent apposition of $5.75 \%$ (Fig. 4). Percent apposition in non-cLIUS-stimulated explants at the end of 14 days was $3.32 \%$ (Fig. 4). Thus, subsequent experiments examining the effect of cytokine on the closure of fissures was performed at cLIUS at $5 \mathrm{MHz}$.

Explants that received cLIUS $(5 \mathrm{MHz})$ in the presence or absence of IL-6 or TNF $\alpha$ displayed closed gaps on day 14 (Fig. 3d-f) and day 28 of culture (Fig. 3j-1). In contrast, non-cLIUS-stimulated explants and explants treated with either IL-6 or TNF $\alpha$ alone displayed intact (Fig. 3a, b) or partially narrowing fissures (Fig. 3c) on day 14, and closed fissures on day 28 of culture (Fig. 3g-i). The quantification of percent apposition corroborated the alcian blue staining results and are shown in Fig. 4. On day 14 in the absence of cytokine, the percent apposition was significantly $(p=0.027)$ increased from $3.32 \%$ in non-cLIUS-stimulated control to $58.04 \%$ under cLIUS. The inclusion of cytokines in the culture medium led to a higher percent apposition in non-cLIUSstimulated controls. The percent apposition remained significantly elevated under cLIUS when compared to noncLIUS-stimulated controls in the presence of IL-6 or TNF $\alpha$. On day 28 in the absence of cytokine, the percent apposition was significantly higher in cLIUS-stimulated 

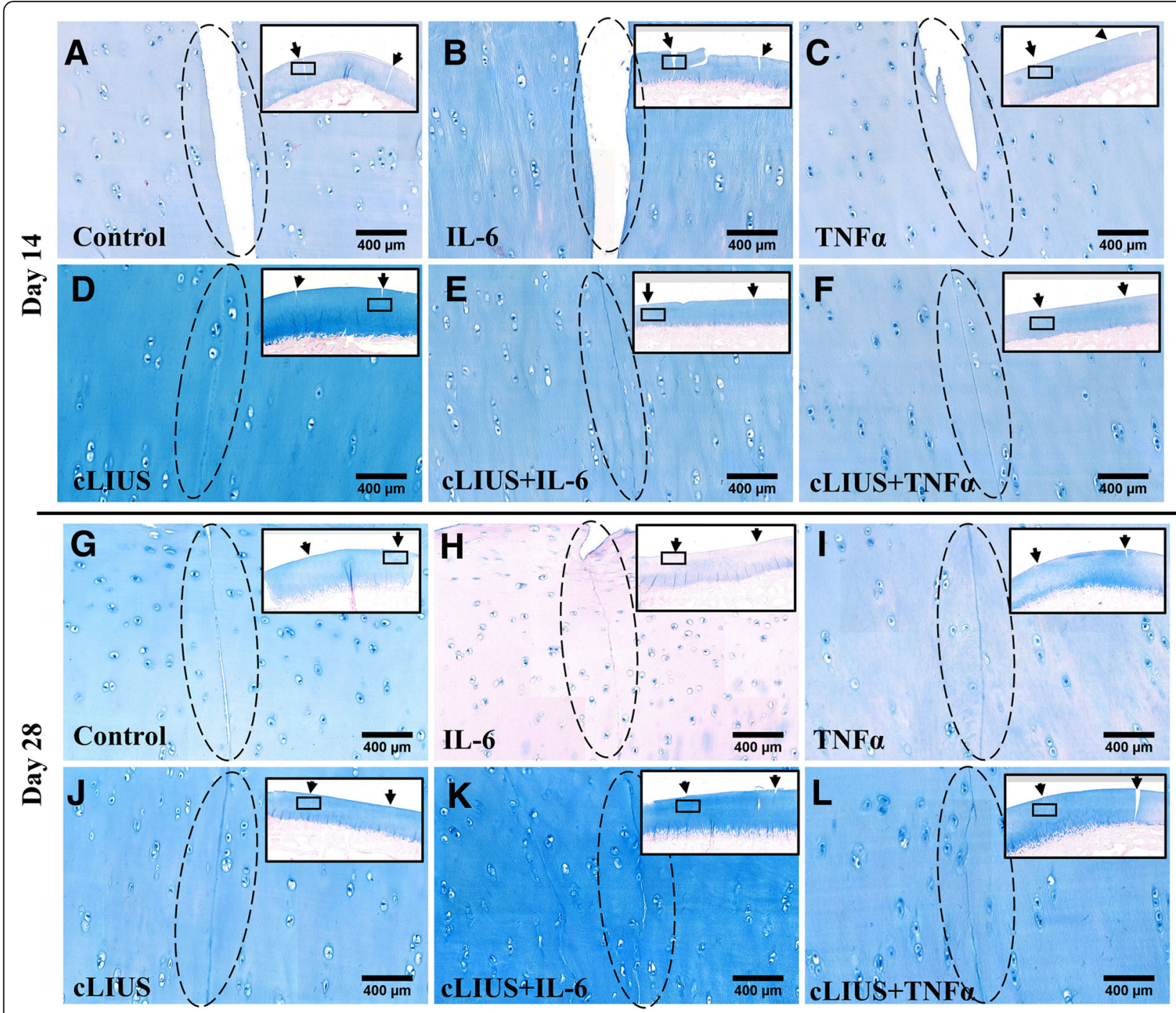

Fig. 3 Alcian blue staining of osteochondral explants. Incised osteochondral explants ( $n=6$ explants per group per time point) were grown in DMEM-F12 medium supplemented with 10\% FBS, $1 \times$ antibiotic-antimycotic solution and $50 \mu \mathrm{g} / \mathrm{ml} \mathrm{L}$-ascorbic acid in the presence or absence of IL-6 or TNFa under cLIUS at $14 \mathrm{kPa}(5 \mathrm{MHz}, 2.5 \mathrm{Vpp}), 20 \mathrm{~min}, 4$ times/day. Non-cLIUS-stimulated explants ( $n=6$ explants per group per time point) served as controls for each treatment condition. Explants were fixed in 10\% neutral buffered formalin and embedded in paraffin. The panel shows $4 \mu \mathrm{m}$ sections of osteochondral explants at the interfacial region stained with alcian blue $(\mathrm{pH} 1)$ after 14 and 28 days in culture at $20 \times$ magnification. Scale bar represents $400 \mu \mathrm{m}$. Insets depict the whole section imaged at $2 \times$ magnification. Black arrows in the insets depict the sites of incision

explants $(p=0.039)$ when compared to non-cLIUS-stimulated control. In contrast, no significant difference was noted between cLIUS and non-cLIUS-stimulated explants in the presence of either IL- 6 or TNF $\alpha$ on day 28 , corresponding to closed fissures observed in Fig. 3 (h, i, k, l).

After 28 days, explants exposed to IL- 6 alone displayed weak alcian blue stain (Fig. 3h), indicating depletion of proteoglycans. In contrast, intense alcian blue stain was noted in IL-6-treated explants that received cLIUS stimulation (Fig. 3k). Further analysis by safranin $\mathrm{O}$ staining displayed noticeable depletion of proteoglycans in explants treated with either IL-6 or TNF $\alpha$ alone
(Fig. 5b-c). cLIUS stimulation of IL-6 or TNF $\alpha$-treated explants showed an intense and homogenous Safranin O stain (Fig. 5e-f). Similarly, after 28 days in culture, immunohistochemical staining of explants for collagen II exhibited weaker staining in non-cLIUS stimulated explants in the presence or absence of IL- 6 or TNF $\alpha$ (Fig. 5g-i) when compared to cLIUS-stimulated explants (Fig. 5j-1).

Taken together, the results indicated that cLIUS at 5 $\mathrm{MHz}$ closed chondral fissures while preserving the proteoglycan and collagen distribution in the presence of IL- 6 or TNFo; thus, demonstrating a chondroprotective effect. 


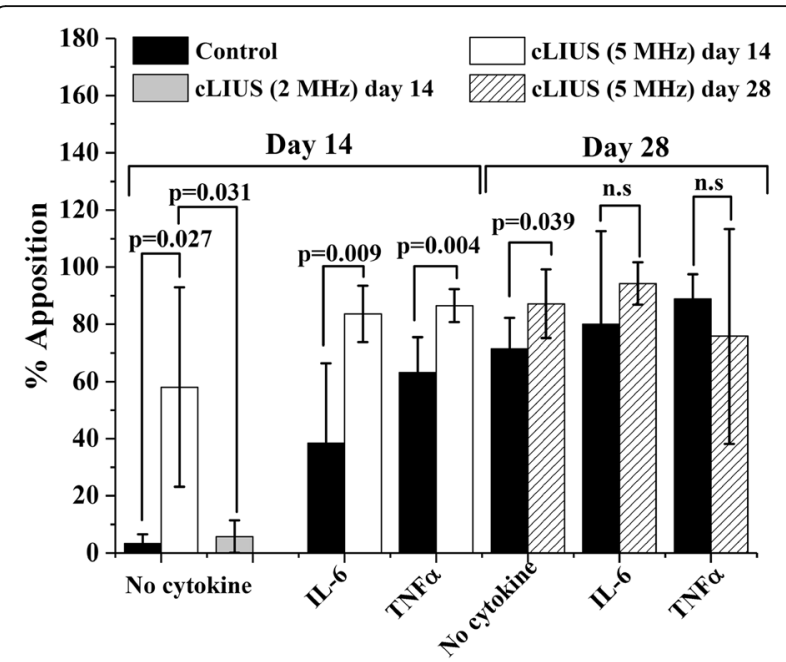

Fig. 4 Percent apposition under CLIUS The length of chondral interfaces in the cartilage and osteochondral explants ( $n=6$ per sample per group per time point) were measured by ImageJ and the percent apposition (closed gaps) was calculated as follows: (length of closed interface/total length of interface) ${ }^{*} 100$. Graph represents the percent apposition in non-cLIUS-treated and cLIUSstimulated explants in the presence or absence of IL-6 or TNFa in osteochondral explants on day 14 and 28 of culture. Data represents a mean \pm standard deviation. Statistically significant differences are indicated by $p$-values and non-significant differences are indicated as n.s

\section{Gene expression profile under cLIUS}

To further ascertain the chondroprotective effect of cLIUS, the expression of select catabolic (MMP13, ADAMTS4) and anabolic genes (Collagen II and TIMP1) were evaluated in cultured chondrocytes by qRT-PCR and shown in Fig. 6. The expression of the transcription factor (NF- $\mathrm{kB}$ ) in regulating the expression of catabolic genes was also assayed. In the absence of any cytokine insult, the exposure of chondrocytes to cLIUS reduced the gene expression of MMP13 $(p=0.037)$ and ADAMTS4 $(p=0.001)$ when compared to non-cLIUS-stimulated controls (indicated by rectangle in Fig. 6a, b). The inclusion of IL-6 or TNF $\alpha$ significantly elevated the gene expression of MMP13 (10.48 \pm 7.43-fold in IL- 6 and $3.55 \pm 1.07$-fold in TNF $\alpha$ ) and ADAMTS4 (92.26 \pm 61.10-fold in IL-6; $2.26 \pm 0.46$-fold in TNF $\alpha$ ) in non-cLIUSstimulated chondrocytes (indicated by open arrows in Fig. 6a, b). Whereas, cLIUS diminished the IL-6 or TNF $\alpha$-induced upregulation of the catabolic markers $(p=0.038$ in cLIUS+IL-6 versus IL-6, and $p=0.004$ in cLIUS+TNF $\alpha$ versus TNF $\alpha$ for MMP13; $p=0.049$ in cLIUS +IL-6 versus IL-6, and $p=0.036$ in cLIUS+TNF $\alpha$ versus TNF $\alpha$ for ADAMTS4), and returned the gene expression to baseline levels observed under cLIUS-stimulation only (indicated by closed arrows in Fig. 6a, b). As anticipated, the exposure of chondrocytes to TNF $\alpha$ led to an increase in the gene expression of NF-kB $(1.44 \pm 0.03$-fold in TNF $\alpha$ versus $1.01 \pm 0.01$-fold in control, $p=0.019$ ) while no discernable differences in NF- $\kappa B$ gene expression were noted when chondrocytes were exposed to IL-6 (Fig. 6c). Under cLIUS, the gene expression of NF- $\mathrm{kB}$ was suppressed in chondrocytes exposed to TNF $\alpha(0.75 \pm 0.13$-fold in cLIUS+ TNF $\alpha$ versus $1.44 \pm 0.03$-fold in TNF $\alpha$, $p=0.046$ ) (Fig. 6c).

The gene expression of the cartilage-specific marker, collagen II, remained significantly elevated (5.85 \pm 0.57 -fold $p=0.004$ versus non-cLIUS-stimulated control) under cLIUS stimulation irrespective of IL-6 (5.88 \pm 0.95 -fold in cLIUS +IL-6 versus $0.89 \pm 0.07$-fold in IL-6; $p=0.009$ ) or TNF $\alpha$ treatment $(5.01 \pm 0.41$-fold in cLIUS+TNF $\alpha$ versus $0.63 \pm$ 0.11 -fold in TNF $\alpha ; p=0.003$ ) (Fig. 6d). Significant increases $(3.15 \pm 1.10$-fold in cLIUS+TNF $\alpha$ versus $0.61 \pm 0.30$-fold in TNF $\alpha, p=0.038$ ) in the gene expression of TIMP1, an anabolic inhibitor of metalloproteinases, was observed when IL-6-treated chondrocytes were exposed to cLIUS (Fig. 6e). TNF $\alpha$ treatment had no significant effect on the gene expression of TIMP1 with or without cLIUS stimulation.

The results indicated that the catabolic genes were downregulated under cLIUS and this downregulation was sustained in the presence of pro-inflammatory cytokines IL-6 and TNF $\alpha$. In addition, cLIUS stimulation demonstrated elevated levels of anabolic genes regardless of cytokine treatment.

\section{Migration of cells under cLIUS}

Increasing the availability of cells for migration at the wound edge has been shown to improve integration of cartilage surfaces [21, 22]. Therefore, cellular migration under cLIUS in the presence of IL- 6 or TNF $\alpha$ was studied in 2D and 3D formats. Migration of cells from the surrounding cartilage tissue into the cell-free central hydrogel core in cartilage-hydrogel constructs was visualized by live (green)/dead (red) staining and presented in Fig. 7 under different treatment conditions. On day 24 , an enhanced cell migration to the hydrogel core was noted in all constructs that received cLIUS stimulation irrespective of IL-6 or TNF $\alpha$ treatment (Fig. 7d-f).

To better explain the results observed in $3 \mathrm{D}$ format in Fig. 7, a 2D scratch was employed to study the migration of adult chondrocytes under cLIUS stimulation in the presence or absence of IL-6 or TNF $\alpha$ and is shown in Fig. 8a. After $48 \mathrm{~h}$ of cLIUS stimulation, the migration of chondrocytes was significantly increased in the presence or absence of IL-6 or TNF $\alpha$, as evidenced by $55.27 \pm 5.07 \%, 78.94$ $\pm 1.65 \%$, and $38.96 \pm 3.89 \%$ coverage of the scratch area in cLIUS, cLIUS+IL-6, and cLIUS+TNF $\alpha$ samples, respectively (indicated by black arrows in Fig. 8b-d). In contrast, the scratch area covered in non-cLIUS stimulated, and chondrocytes treated with IL- 6 or TNF $\alpha$ alone was significantly reduced 


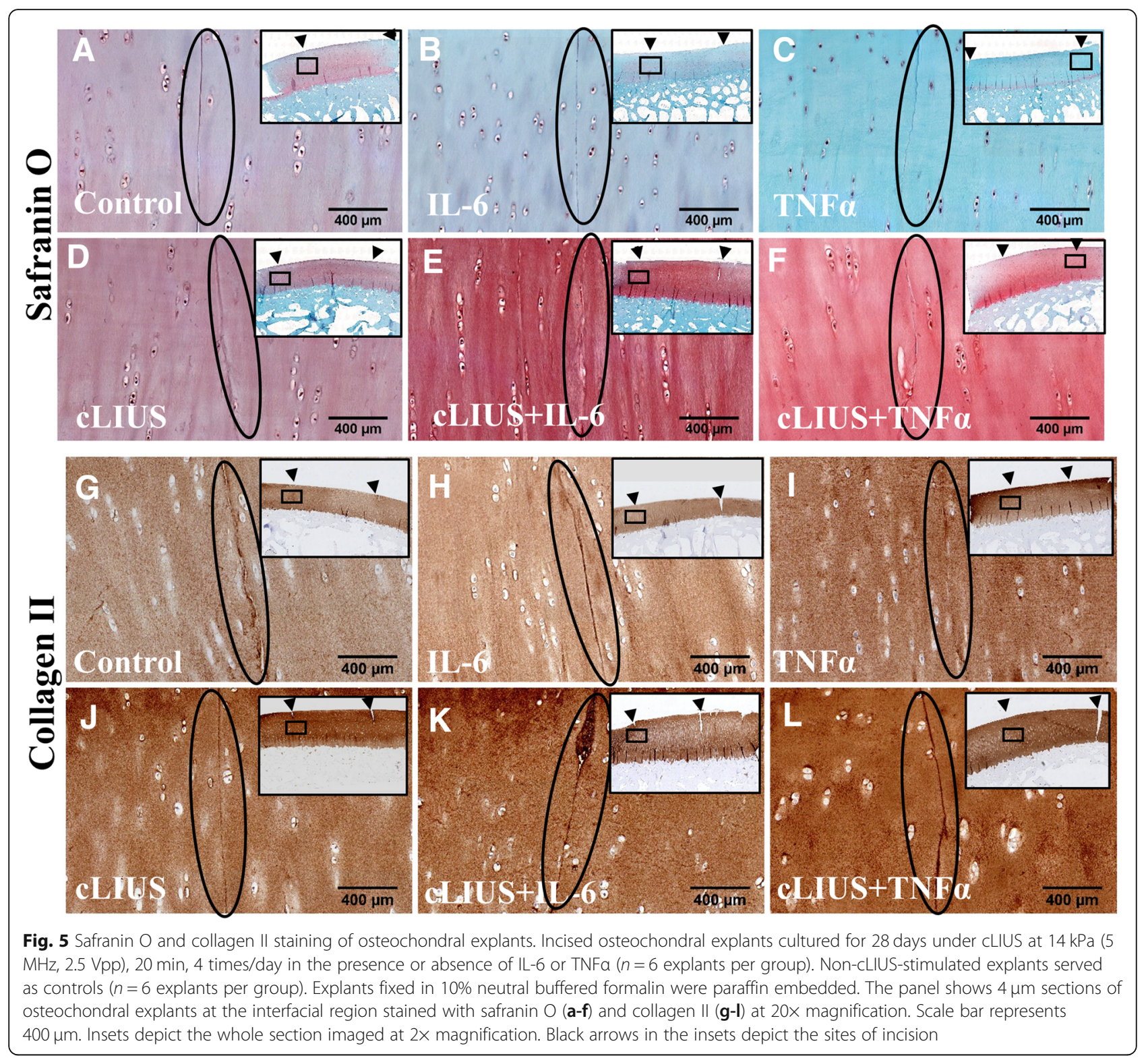

to $28.53 \pm 4.94 \%, 22.62 \pm 18.39 \%$ and $11.99 \pm 2.67 \%$ respectively.

\section{Discussion}

Cartilage repair protocols that promote integration with the native tissue while mitigating the catabolic effects of a pro-inflammatory environment and maintaining the cartilage phenotype are of interest. The negative effects of catabolic cytokines on cartilage have been well documented [23], however, to our knowledge studies demonstrating repair of cartilage fissures in a catabolic environment, albeit in vitro, has not been reported. Elevated levels of IL- 6 and TNF $\alpha$ in the injured cartilage were implicated in the IL- 6 and TNF $\alpha$-mediated cartilage degradation [7]. Moderate dynamic compression and
pLIUS was previously shown to mitigate the cytokineinduced catabolic effects $[11,17]$ in cartilage explants via the suppression of NF- $\mathrm{kB}$. Our study combines an established in vitro cartilage integration model with catabolic conditions imparted by IL- 6 or TNF $\alpha$ and demonstrates that when compared to non-cLIUS-stimulated explants: (1) chondral fissures were repaired expeditiously by cLIUS at 5 $\mathrm{MHz}$ in the absence of cytokines; (2) the expeditious repair of chondral fissures by cLIUS at $5 \mathrm{MHz}$ was further achieved in the presence of IL- 6 and TNF $\alpha$; (3) IL-6 and TNF $\alpha$-induced catabolic effects on cartilage was rescued by cLIUS. In explants exposed to cLIUS applied at the non-resonant frequency of $2 \mathrm{MHz}$, the chondral fissures remained open and the percent apposition was not significantly different from non-cLIUS-stimulated controls. 

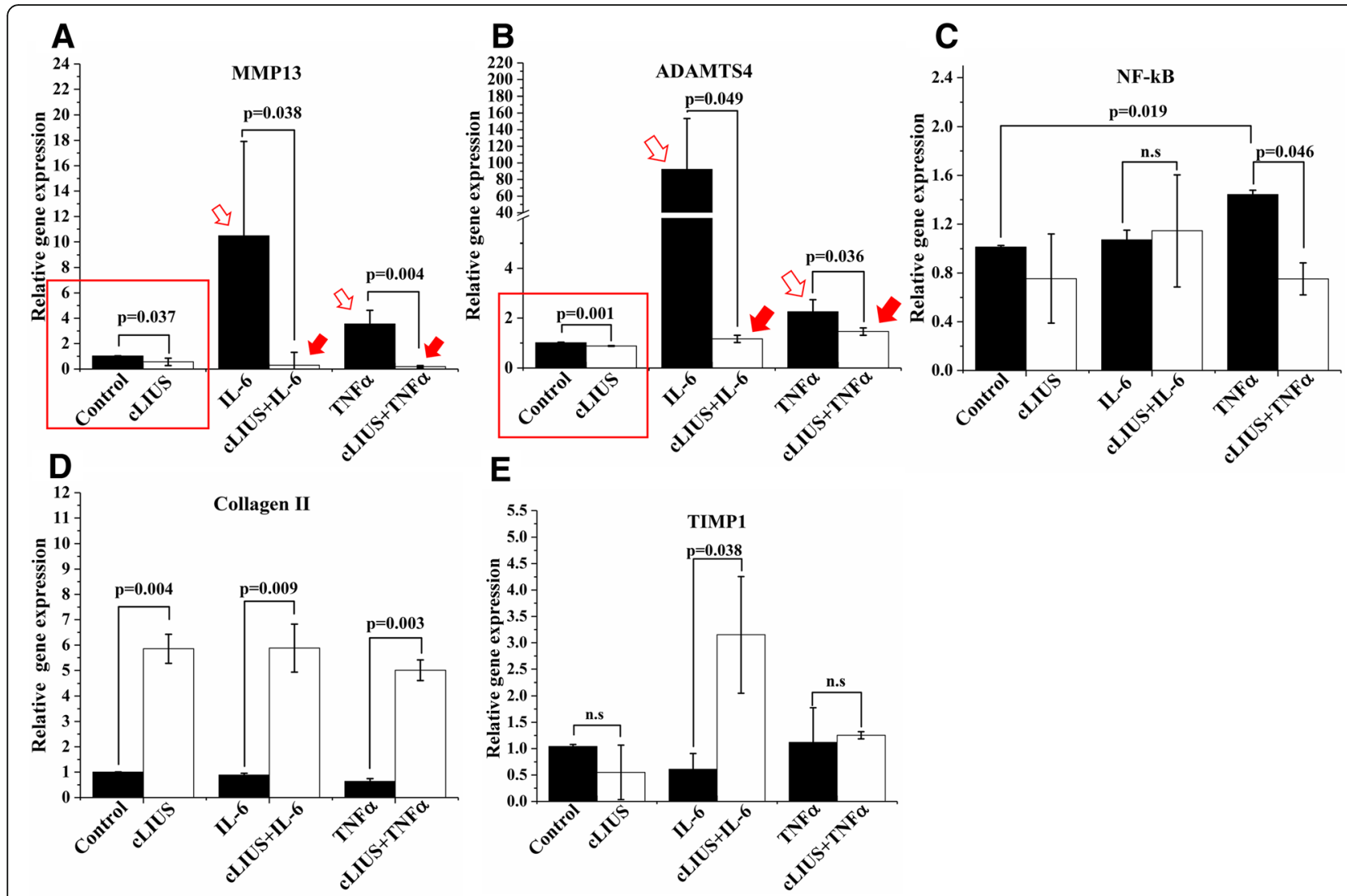

Fig. 6 qRT-PCR analysis of the catabolic and anabolic gene expression in chondrocytes. Bovine articular chondrocytes cultured in DMEM-F12 medium supplemented with $10 \% \mathrm{FBS}, 1 \times$ antibiotic-antimycotic solution and $50 \mu \mathrm{g} / \mathrm{ml}$ L-ascorbic acid at an initial seeding density of $2 \times 10^{5}$ cells/well were subjected to cytokine treatment $(n=3)$ followed by cLIUS stimulation at $14 \mathrm{kPa}(5 \mathrm{MHz}, 2.5 \mathrm{Vpp})$ for 5 min. Non-cLIUS-stimulated explants served as controls $(n=3)$. Homogenates from 2 wells per group served as one replicate and 3 such replicates were used for analysis $(n=3)$. Total RNA was extracted and the gene expression of (a) MMP13, (b) ADAMTS4, (c) NF-KB, (d) Collagen II and (e) TIMP1 was evaluated by qRT-PCR. Bar graph represents mean $\pm 95 \%$ confidence interval, $p$ values indicate statistically significant differences and n.s represents non-significant differences

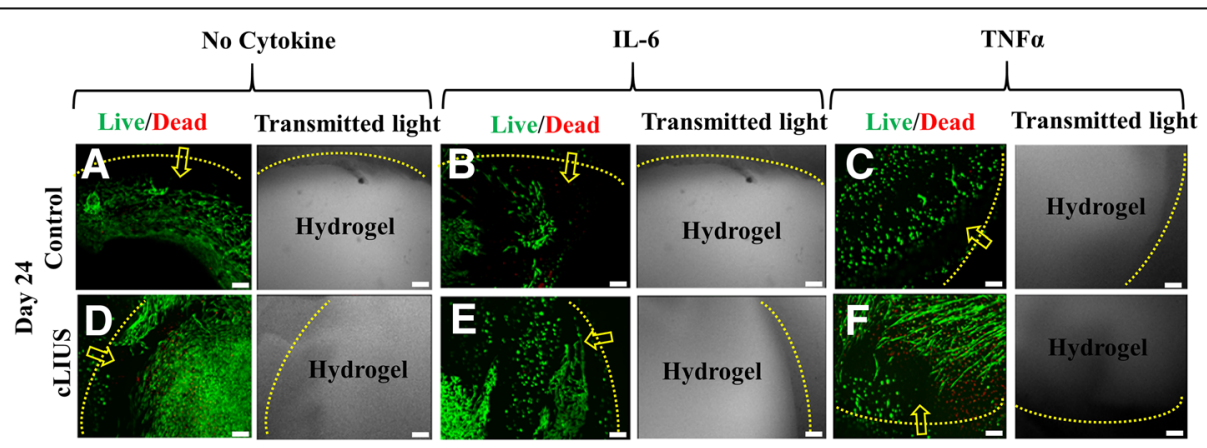

Fig. 7 Cell migration to the hydrogel core from the surrounding cartilage in cartilage-hydrogel constructs. A 4 mm chondral core in osteochondral explants was excised using a biopsy punch and filled with cell-free $1 \%$ agarose hydrogel to form cartilage-hydrogel constructs and cultured in DMEM-F12 medium supplemented with 10\% FBS, $1 \times$ antibiotic-antimycotic solution and $50 \mu \mathrm{g} / \mathrm{ml} \mathrm{L}$-ascorbic acid for 24 days in the presence or absence of IL- 6 or TNFa. Constructs $(n=3)$ were exposed to cLIUS at $14 \mathrm{kPa}(5 \mathrm{MHz}, 2.5 \mathrm{Vpp}), 20 \mathrm{~min}, 4$ times/day (d-f). Non-cLIUSstimulated constructs $(n=3)$ served as controls $(\mathbf{a}-\mathbf{c})$. Confocal micrographs demonstrate infiltrated cells from the surrounding cartilage into the hydrogel core when stained with $6 \mu \mathrm{M}$ calcein $^{\mathrm{AM}}$ (green) and $4 \mu \mathrm{M}$ ethidium homodimer-I (red) on day 24 of culture. Live cells are represented in green and yellow arrows indicate the direction of the migration of cells from the surrounding cartilage to the hydrogel core. Yellow dotted line shows the boundary between the hydrogel core and the surrounding cartilage. Transmitted light micrographs shows the phase-contrast image of hydrogel-cartilage constructs. Scale bar represents $100 \mu \mathrm{m}$ 


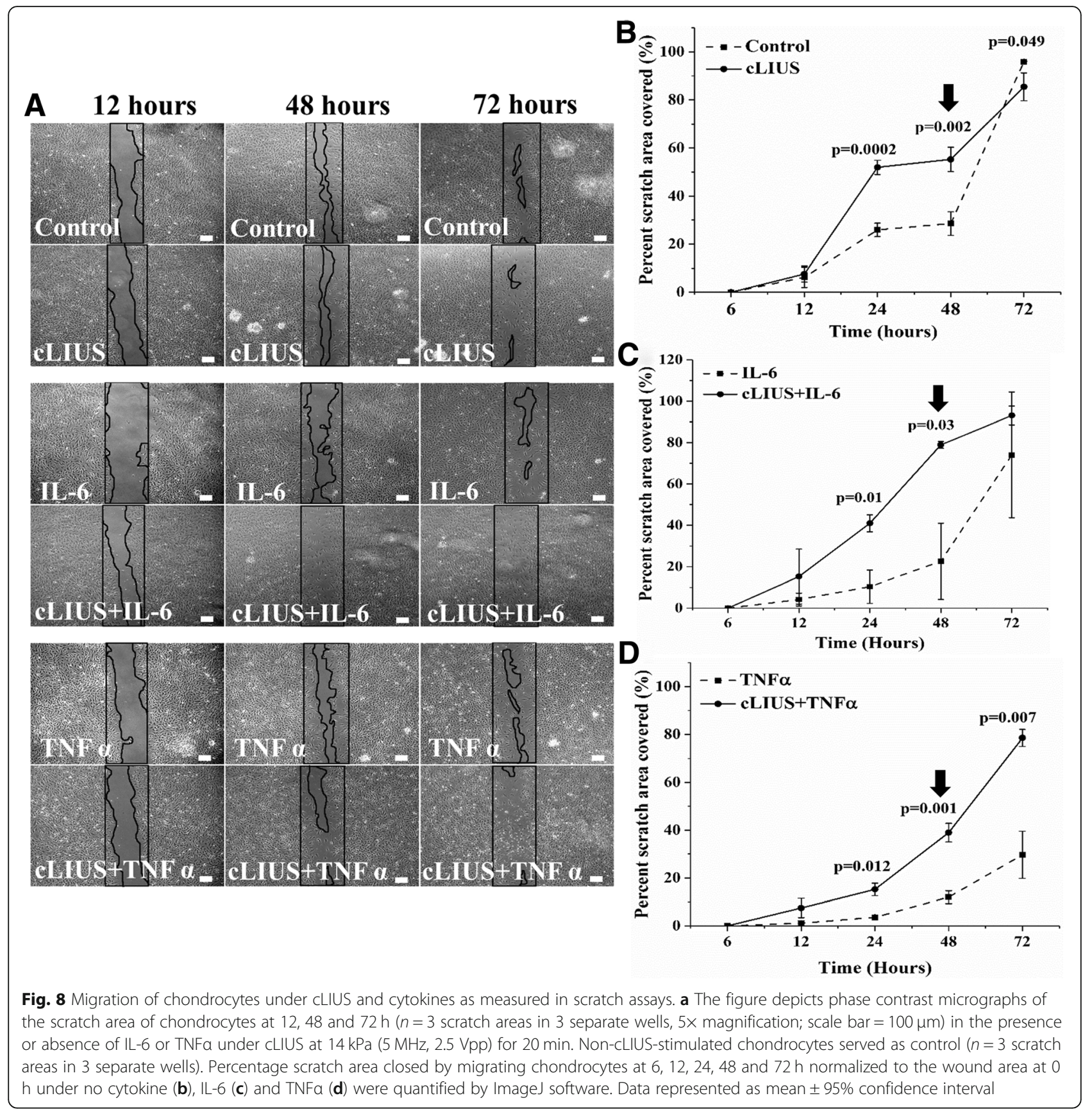

Most pharmacological interventions that employ anti-cytokine agents such as receptor antagonists for IL-1 $\beta$, IL-6 or TNF $\alpha$ [24-26] and chondroprotective drugs $[27,28]$, are target-specific, abrogating the effect of a particular cytokine $[7,8]$. However, targeting an individual cytokine may not be sufficiently effective in reducing the overall inflammatory response. Further, toxicity and adverse side-effects associated with the administration of anti-inflammatory agents hinder their long-term clinical usage [10]. Thus, a treatment modality that attenuates the effects of potent pro-inflammatory cytokines is required. The current study demonstrated the ability of cLIUS in suppressing the effects of two potent catabolic cytokines namely IL-6, and TNF $\alpha$.

The expression of catabolic enzymes MMPs and ADAMTs that degrade collagens and aggrecanases respectively are elevated in injured cartilage [7, 29], and the catabolic response upon injury is exacerbated by the synergistic effects conferred by the pro-inflammatory cytokines including IL- 6 and TNF $\alpha[9,29]$. In an environment of accelerated matrix degradation, the anabolic response to synthesize matrix falls 
behind [30,31] and is often suppressed upon pathological progression. Thus, increased matrix turnover to overcome catabolic effects in injured cartilage is desirable. Anti-inflammatory therapeutic agents, while noted to rescue cartilage from proteoglycan loss under inflammation, do not have an effect on anabolic gene expression [32, 33]. In the present study, significant upregulation in the anabolic response of chondrocytes as evidenced by 5.85 -fold increases in collagen II (Fig. 6d) and 3.15-fold increase in TIMP1 gene expression under cLIUS (Fig. 6e) accompanied the downregulation of catabolic genes, MMP13 and ADAMTS4 upon cLIUS stimulation in the presence of IL- 6 or TNF $\alpha$ (Fig. 6a, b). Additionally, the expression of anabolic genes observed under cLIUS was consistent with the higher intensity of collagen and proteoglycan staining noted in explants (Fig. 5d-f, j-l). Collectively, cLIUS elicited a coordinated response that promoted cartilaginous matrix synthesis while simultaneously protecting the matrix from IL- 6 or TNF $\alpha$-induced degradation.

The key transcription factor, NF- $\mathrm{kB}$, regulates inflammation by inducing the expression of pro-inflammatory cytokines and mediators, including TNF $\alpha$ which in turn potentiates activation of NF- $\mathrm{KB}[34,35]$. The inhibition of TNF $\alpha$-induced upregulation of NF- $\mathrm{KB}$ by cLIUS in the present study (Fig. 6c) demonstrated the effective modulation of the NF-kB inflammation pathway in chondrocytes by cLIUS. Evidence of complete abrogation of IL- $1 \beta$-induced NF- $\mathrm{kB}$ activation upon LIUS stimulation in a previous study [11] lends further credence to the overall anti-inflammatory effect of LIUS. Differently from the NF- $\mathrm{kB}$ pathway, IL- 6 induces the expression of catabolic genes via the STAT3 pathway [36]. Therefore, the expression of NF-kB remained unaffected by IL-6 insult in the present study. However, elevated levels of TIMP1 expression may have rescued the IL-6-induced catabolic effects when exposed to cLIUS (Fig. 6e).

In the local milieu of the inflamed joint, an increase in the antagonistic factors that impede the migration of cells to the injured site is counterproductive to integrative repair strategies [21, 22, 37, 38]. Among the plethora of chemokines released upon inflammation; some invoke recruitment of resident and progenitor cells to initiate repair while others inhibit migration of cells. Notably, TNF $\alpha$ has been implicated in impeding cell migration [39] while IL-6 is known to support migration [40]. Both in the presence and absence of IL- 6 or TNF $\alpha$, an expeditious repair of chondral fissures noted under cLIUS, was attributed to the enhanced migration of cells.

Elongated cells were observed in TNF $\alpha$-treated cartilagehydrogel constructs (Fig. 7c, f). The cause of altered cell morphology observed is uncertain. Decreased hydrogel stiffness at lower concentrations of agarose $(\sim 1 \%$ agarose) was shown to affect cell shape [41]. Also, progenitor cells often display an elongated cell morphology [42] and are reported to possess greater migratory potential [43-45]. Thus, the modified cellular morphology observed could be attributed to a combination of factors, including the biophysical properties of the hydrogel and the nature of the migrating cells. Therefore, further investigations centering on the identity of migrating cells, morphological response to external physical and chemical forces including cLIUS, cytokine and/or biomaterial will be undertaken in the future. Therapeutic doses of cLIUS below $500 \mathrm{~mW} / \mathrm{cm}^{2}$ do not have an adverse effect on bone growth [46]. As the cLIUS regimen employed in this study was less than $<20 \mathrm{~mW} / \mathrm{cm}^{2}$, the impact of cLIUS on the bone was not investigated. However, the impact of cLIUS on both the bone and cartilage will be studied in future in vivo studies. Further, the thermal effects of cLIUS on cartilage was also not investigated in the current study as cLIUS intensity less than $20 \mathrm{~mW} / \mathrm{cm}^{2}$ was not shown to elicit any thermal effects [15].

\section{Conclusions}

Synergistic rehabilitative regeneration methods that overcome the adverse catabolic effects of the pro-inflammatory joint environment while simultaneously promoting chondroregeneration are paramount to achieving joint restoration in the long-term. Taken together [11], results demonstrated the potential of cLIUS as a pro-anabolic, anti-catabolic and chondroprotective therapy for applications in rehabilitative regeneration programs for cartilage repair. The translation of promising in-vitro finding regarding cLIUS necessitates an understanding of the propagation of cLIUS through the joint space, an ongoing study in our laboratory.

\section{Additional file}

Additional file 1: Figure S1. Alcian Blue staining of osteochondral explants under CLIUS at $2 \mathrm{MHz}$. Incised osteochondral explants were exposed to CLIUS at a non-resonant frequency of $2 \mathrm{MHz}$ at $14 \mathrm{kPa}$ (6 Vpp), $20 \mathrm{~min} /$ application, 4 applications/day for a period of 14 days in culture $(n=6)$. Non-cLIUS-stimulated explants served as controls $(n=6)$. Explants were fixed in 10\% neutral buffered formalin and embedded in paraffin. Figure shows $4 \mu \mathrm{m}$ sections of osteochondral explants at the interfacial region stained with alcian blue $(\mathrm{pH} 1)$ after 14 days in culture at $20 \times$ magnification. Scale bar represents $100 \mu \mathrm{m}$. Inserts depict the whole section imaged at $2 \times$ magnification. (TIF $9326 \mathrm{~kb}$ )

\section{Abbreviations}

ACl: Autologous chondrocyte implantation; ADAMTS: A disintegrin and metalloproteinase with thrombospondin motifs; ANOVA: analysis of variance; CLIUS: Continuous low-intensity ultrasound; DMEM: Dulbecco's modified eagle medium; FBS: Fetal bovine serum; GAG: Glycosaminoglycan; IL: Interleukin; LIUS: low-intensity ultrasound; MMP: Matrix metallopeptidase; OA: Osteoarthritis; pLIUS: Pulsed low-intensity ultrasound; TCP: Tissue culture plate; TIMP: Tissue inhibitor of metallopeptidase; TNF: Tumor necrosis factor

\section{Acknowledgments}

We extend our gratitude to Teresa Fangman of Morrison Microscopy Core Research Facility at UNL for assistance with confocal imaging, and Melissa Holzapfel of Tissue Sciences Facility at the University of Nebraska Medical Center for assistance with histology. 


\section{Funding}

We are grateful to the Nebraska Research Initiative for funding and support. The funding source had no role in the design of study, data collection, analysis, data interpretation or in the writing of the manuscript.

\section{Availability of data and materials}

All datasets generated and/or analyzed during the current study are available from the corresponding author on reasonable request.

\section{Authors' contributions}

NS, HV and AS conceived and designed the study. NS carried out experiments, analyzed and interpreted data, drafted the manuscript. NS and AS take responsibility for the integrity of the work from inception to completion. NS, HV and AS revised and approved the final version of the manuscript.

\section{Ethics approval and consent to participate}

Not Applicable.

\section{Consent for publication}

Not Applicable.

\section{Competing interests}

The authors declare that they have no competing interests.

\section{Publisher's Note}

Springer Nature remains neutral with regard to jurisdictional claims in published maps and institutional affiliations.

\section{Author details \\ ${ }^{1}$ Department of Chemical and Biomolecular Engineering, University of Nebraska-Lincoln, Lincoln, NE 68588-0643, USA. ²Department of Chemical and Materials Engineering, University of Alabama at Huntsville, Huntsville, Alabama 35899, USA.}

\section{Received: 14 December 2018 Accepted: 11 April 2019}

\section{Published online: 04 May 2019}

\section{References}

1. Nawaz SZ, Bentley G, Briggs TWR, Carrington RWJ, Skinner JA, Gallagher KR, et al. Autologous chondrocyte implantation in the knee: mid-term to Longterm results. J Bone Surg Am. 2014;96(10):824-30.

2. Goyal D, Keyhani S, Lee EH, Hui JH. Evidence-based status of microfracture technique: a systematic review of level I and II studies. Arthroscopy. 2013; 29(9):1579-88.

3. Niemeyer P, Pestka JM, Kreuz PC, Erggelet C, Schmal H, Suedkamp NP, et al. Characteristic complications after autologous chondrocyte implantation for cartilage defects of the knee joint. Am J Sports Med. 2008;36(11):2091-9.

4. Krych AJ, Hevesi M, Desai VS, Camp CL, Stuart MJ, Saris DBF. Learning from failure in cartilage repair surgery: An analysis of the mode of failure of primary procedures in consecutive cases at a tertiary referral center. Orthop J Sports Med. 2018;6(5):2325967118773041.

5. Djouad F, Rackwitz L, Song $Y$, Janjanin S, Tuan RS. ERK1/2 activation induced by inflammatory cytokines compromises effective host tissue integration of engineered cartilage. Tissue Eng Part A. 2009;15(10):2825-35.

6. Anderson DD, Chubinskaya S, Guilak F, Martin JA, Oegema TR, Olson SA, et al. Post-traumatic osteoarthritis: improved understanding and opportunities for early intervention. J Orthop Res. 2011:29(6):802-9.

7. Tsuchida Al, Beekhuizen M, t Hart MC, Radstake TR, Dhert WJ, Saris DB, et al. Cytokine profiles in the joint depend on pathology, but are different between synovial fluid, cartilage tissue and cultured chondrocytes. Arthritis Res Ther 2014;16(5):441.

8. Bigoni M, Turati M, Sacerdote P, Gaddi D, Piatti M, Castelnuovo A, et al. Characterization of synovial fluid cytokine profiles in chronic meniscal tear of the knee. J Orthop Res. 2017:35(2):340-6.

9. Sui Y, Lee JH, DiMicco MA, Vanderploeg EJ, Blake SM, Hung HH, et al. Mechanical injury potentiates proteoglycan catabolism induced by interleukin-6 with soluble interleukin-6 receptor and tumor necrosis factor alpha in immature bovine and adult human articular cartilage. Arthritis Rheum. 2009;60(10):2985-96.
10. Dancevic CM, McCulloch DR. Current and emerging therapeutic strategies for preventing inflammation and aggrecanase-mediated cartilage destruction in arthritis. Arthritis Res Ther. 2014;16(5):429.

11. Uddin SM, Richbourgh B, Ding Y, Hettinghouse A, Komatsu DE, Qin YX, et al. Chondro-protective effects of low intensity pulsed ultrasound. Osteoarthr Cartil. 2016:24(11):1989-98.

12. Louw T, Whitney $S$, Subramanian A, Viljoen $H$. Forced wave motion with internal and boundary damping. J Appl Phys 2012;111(1):014702-014708.

13. Louw TM, Budhiraja G, Viljoen HJ, Subramanian A. Mechanotransduction of ultrasound is frequency dependent below the cavitation threshold. Ultrasound Med Biol. 2013;39(7):1303-19.

14. Miller AD, Chama A, Louw TM, Subramanian A, Viljoen HJ. Frequency sensitive mechanism in low-intensity ultrasound enhanced bioeffects. PLoS One. 2017;12(8):e0181717.

15. Subramanian A, Turner JA, Budhiraja G, Thakurta SG, Whitney NP, Nudurupati SS. Ultrasonic bioreactor as a platform for studying cellular response. Tissue Eng Part C Methods. 2013:19(3):244-55.

16. Stone AV, Loeser RF, Vanderman KS, Long DL, Clark SC, Ferguson CM. Pro inflammatory stimulation of meniscus cells increases production of matrix metalloproteinases and additional catabolic factors involved in osteoarthritis pathogenesis. Osteoarthr Cartil. 2014;22(2):264-74.

17. Li Y, Frank EH, Wang Y, Chubinskaya S, Huang HH, Grodzinsky AJ. Moderate dynamic compression inhibits pro-catabolic response of cartilage to mechanical injury, TNF-a and IL-6, but accentuates degradation above a strain threshold. Osteoarthr Cartil. 2013;21(12):1933-41.

18. Noriega S, Mamedov T, Turner JA, Subramanian A. Intermittent applications of continuous ultrasound on the viability, proliferation, morphology, and matrix production of chondrocytes in 3D matrices. Tissue Eng. 2007;13(3):611-8.

19. Budhiraja G, Sahu N, Subramanian A. Low-intensity ultrasound upregulates the expression of cyclin-D1 and promotes cellular proliferation in human mesenchymal stem cells. Biotechnol J. 2018;13(4):e1700382.

20. Theodoropoulos JS, DeCroos AJ, Petrera M, Park S, Kandel RA. Mechanical stimulation enhances integration in an in vitro model of cartilage repair. Knee Surg Sports Traumatol Arthrosc. 2016;24(6):2055-64.

21. Pabbruwe MB, Esfandiari E, Kafienah W, Tarlton JF, Hollander AP. Induction of cartilage integration by a chondrocyte/collagen-scaffold implant. Biomaterials. 2009;30(26):4277-86.

22. Gilbert SJ, Singhrao SK, Khan IM, Gonzalez LG, Thomson BM, Burdon D, et al. Enhanced tissue integration during cartilage repair in vitro can be achieved by inhibiting chondrocyte death at the wound edge. Tissue Eng Part A. 2009;15(7):1739-49.

23. Guilak F, Fermor B, Keefe FJ, Kraus VB, Olson SA, Pisetsky DS, et al. The role of biomechanics and inflammation in cartilage injury and repair. Clin Orthop Relat Res. 2004;423:17-26.

24. Kimmerling KA, Furman BD, Mangiapani DS, Moverman MA, Sinclair SM, Huebner $J \mathrm{~L}$, et al. Sustained intra-articular delivery of IL-1RA from a thermally-responsive elastin-like polypeptide as a therapy for post-traumatic arthritis. Eur Cell Mater. 2015;29:124-40.

25. Kawaguchi A, Nakaya $H$, Okabe T, Tensho K, Nawata M, Eguchi $Y$, et al. Blocking of tumor necrosis factor activity promotes natural repair of osteochondral defects in rabbit knee. Acta Orthop. 2009;80(5):606-11.

26. Hashizume M, Tan SL, Takano J, Ohsawa K, Hasada I, Hanasaki A, et al. Tocilizumab, a humanized anti-IL-6R antibody, as an emerging therapeutic option for rheumatoid arthritis: molecular and cellular mechanistic insights. Int Rev Immunol. 2015;34(3):265-79.

27. Miyakoshi N, Kobayashi M, Nozaka K, Okada K, Shimada Y, Itoi E. Effects of intraarticular administration of basic fibroblast growth factor with hyaluronic acid on osteochondral defects of the knee in rabbits. Arch Orthop Trauma Surg. 2005;125(10):683-92.

28. Strauss E, Schachter A, Frenkel S, Rosen J. The efficacy of intra-articular hyaluronan injection after the microfracture technique for the treatment of articular cartilage lesions. Am J Sports Med. 2009:37(4):720-6.

29. Patwari P, Cook MN, DiMicco MA, Blake SM, James IE, Kumar S, et al Proteoglycan degradation after injurious compression of bovine and human articular cartilage in vitro: interaction with exogenous cytokines. Arthritis Rheum. 2003:48(5):1292-301.

30. Cawston T, Billington C, Cleaver C, Elliott S, Hui W, Koshy P, et al. The regulation of MMPs and TIMPs in cartilage turnover. Ann N Y Acad Sci. 1999:878:120-9.

31. Aurich M, Squires GR, Reiner A, Mollenhauer JA, Kuettner KE, Poole AR, et al. Differential matrix degradation and turnover in early cartilage lesions of human knee and ankle joints. Arthritis Rheum. 2005;52(1):112-9. 
32. Lu YCS, Evans CH, Grodzinsky AJ. Effects of short-term glucocorticoid treatment on changes in cartilage matrix degradation and chondrocyte gene expression induced by mechanical injury and inflammatory cytokines. Arthritis Res Ther. 2011:13(5):R142-R.

33. Hu T, Xu H, Wang C, Qin H, An Z. Magnesium enhances the chondrogenic differentiation of mesenchymal stem cells by inhibiting activated macrophage-induced inflammation. Sci Rep. 2018;8(1):3406

34. Marcu KB, Otero M, Olivotto E, Borzi RM, Goldring MB. NF-KB signaling: multiple angles to target OA. Curr Drug Targets. 2010;11(5):599-613.

35. Schutze $\mathrm{S}$, Wiegmann $\mathrm{K}$, Machleidt T, Kronke M. TNF-induced activation of NF-kappa B. Immunobiology. 1995;193(2-4):193-203.

36. Tanaka T, Kishimoto T. The biology and medical implications of interleukin6. Cancer Immunol Res. 2014;2(4):288-94.

37. McGregor A, Amsden BG, Waldman SD. Chondrocyte repopulation of the zone of death induced by osteochondral harvest. Osteoarthr Cartil. 2011;19(2):242-8.

38. Tew SR, Kwan AP, Hann A, Thomson BM, Archer CW. The reactions of articular cartilage to experimental wounding: role of apoptosis. Arthritis Rheum. 2000;43(1):215-25.

39. Joos H, Wildner A, Hogrefe C, Reichel H, Brenner RE. Interleukin-1 beta and tumor necrosis factor alpha inhibit migration activity of chondrogenic progenitor cells from non-fibrillated osteoarthritic cartilage. Arthritis Res Ther. 2013;15(5):R119.

40. Tang CH, Chen CF, Chen WM, Fong YC. IL-6 increases MMP-13 expression and cell motility in human chondrosarcoma cells. J Biol Chem. 2011;286(13):11056-66.

41. Karim A, Hall AC. Chondrocyte morphology in stiff and soft agarose gels and the influence of fetal calf serum. J Cell Physiol. 2017;232(5):1041-52

42. Marcus P, De Bari C, Dell'Accio F, Archer CW. Articular Chondroprogenitor cells maintain Chondrogenic potential but fail to form a functional matrix when implanted into muscles of SCID mice. Cartilage. 2014;5(4):231-40.

43. Dowthwaite GP, Bishop JC, Redman SN, Khan IM, Rooney P, Evans DJ, et al. The surface of articular cartilage contains a progenitor cell population. J Cell Sci. 2004;117(Pt 6):889-97.

44. Schminke B, Miosge N. Cartilage repair in vivo: the role of migratory progenitor cells. Curr Rheumatol Rep. 2014;16(11):461.

45. Seol D, McCabe DJ, Choe H, Zheng H, Yu Y, Jang K, et al. Chondrogenic progenitor cells respond to cartilage injury. Arthritis Rheum. 2012;64(11):3626-37.

46. Lyon R, Liu XC, Meier J. The effects of therapeutic vs. high-intensity ultrasound on the rabbit growth plate. J Orthop Res. 2003;21(5):865-71.

Ready to submit your research? Choose BMC and benefit from:

- fast, convenient online submission

- thorough peer review by experienced researchers in your field

- rapid publication on acceptance

- support for research data, including large and complex data types

- gold Open Access which fosters wider collaboration and increased citations

- maximum visibility for your research: over $100 \mathrm{M}$ website views per year

At $\mathrm{BMC}$, research is always in progress.

Learn more biomedcentral.com/submissions 